Portland State University

PDXScholar

3-1-2018

\title{
The Effect of Zn2+ Binding on the Chemistry of Tm3+ and Eu3+ Chelates
}

Diana King

Portland State University

Follow this and additional works at: https://pdxscholar.library.pdx.edu/honorstheses Let us know how access to this document benefits you.

Recommended Citation

King, Diana, "The Effect of Zn2+ Binding on the Chemistry of Tm3+ and Eu3+ Chelates" (2018). University Honors Theses. Paper 516.

https://doi.org/10.15760/honors.521

This Thesis is brought to you for free and open access. It has been accepted for inclusion in University Honors Theses by an authorized administrator of PDXScholar. Please contact us if we can make this document more accessible: pdxscholar@pdx.edu. 


\title{
The Effect of $\mathrm{Zn}^{2+}$ Binding on the Chemistry of $\mathrm{Tm}^{3+}$ and $\mathrm{Eu}^{3+}$ Chelates
}

\author{
By \\ Diana King \\ An undergraduate honors thesis submitted in partial fulfillment of the \\ requirements for the degree of \\ Bachelor of Science \\ in \\ University Honors \\ and \\ Biology
}

Thesis Advisor

Mark Woods B.Sc. (Hons), Ph.D.

Portland State University

2018 


\begin{abstract}
Current contrast agents for MRI are $\mathrm{Gd}^{3+}$-based, which successfully enhance image contrast. These agents, however, are limited in detecting certain analytes associated with disease compared to new agents that operate through a CEST mechanism. In this study, both $\mathrm{Eu}^{3+}$ and $\mathrm{Tm}^{3+}$ chelates were examined as CEST agents for MRI imaging as a function of $\mathrm{Zn}^{2+}$ concentration. $\mathrm{T}_{1}$ values were obtained using NMR spectrometry; these values were then used to fit the CEST data obtained for the compounds. The CEST spectra of the $\mathrm{Tm}^{3+}$ chelate were useful for examining CEST arising from the amide protons. A shift in the amide protons was observed as $\mathrm{Zn}^{2+}$ concentrations increased indicating a presence of multiple species and a change in coordination chemistry. The change of the amide peak at -52 ppm showed its potential to be used as a marker for $\mathrm{Zn}^{2+}$ concentration. The $\mathrm{Eu}^{3+}$ chelate was useful for examining CEST arising from the coordinated water. A distinct change in the water peak shape, intensity, and shift was observed as $\mathrm{Zn}^{2+}$ was added, showing increased water exchange kinetics.
\end{abstract}




\section{INTRODUCTION}

Over time, magnetic resonance imaging has become an indispensable tool both in diagnostic medicine as well as biomedical research. The mechanism by which MRI obtains images is through the principle of Nuclear Magnetic Resonance (NMR). If a sample is placed in a magnet the spins of the nuclei either orient along or against the magnetic field with the majority of the spins aligned along the magnetic field. ${ }^{18}$ The bulk magnetization is therefore aligned along the $\mathrm{z}$ axis as seen in Figure $1 .{ }^{18}$ The net magnetization has a torque and precesses at a specific frequency called the Larmor frequency. ${ }^{12}$ This precessing magnetic field causes a current in a nearby magnetic coil, which generates a signal. A radiofrequency pulse is then applied which results in more spins being oriented against the magnetic field and reduces the bulk magnetization. ${ }^{18}$ The intensity of the signals produced in experiments with NMR and MRI are proportional to the net magnetization. Radiofrequency energy can be applied to the net magnetization causing two effects depending on the duration of the pulse. If a short duration, high power, pulse is applied excitation of the nuclei is observed. If a long duration, low power, pulse is applied saturation will occur. When energy is no longer added, the spins will relax back to their original, low energy- $\alpha$, states.

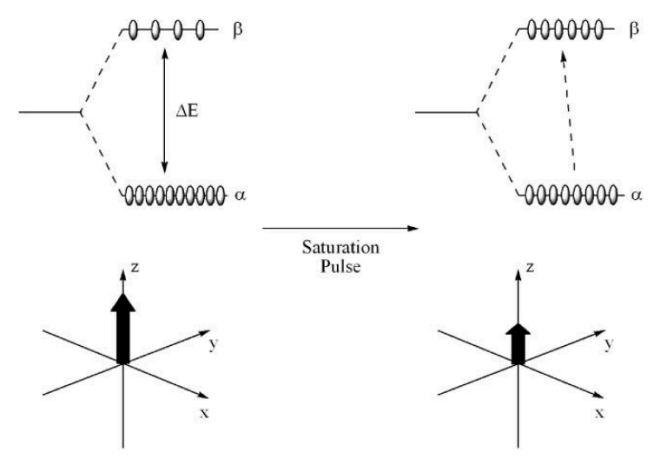

Figure 1. The vector on the $\mathrm{z}$ axis represents the bulk magnetization of a sample (left). A radiofrequency pulse results in more high energy- $\beta$ spins and a lower magnitude of the bulk magnetization (right). ${ }^{18}$ 
Often times in MRI differentiating between different tissue types is difficult and an exogenous agent must be used. These exogenous agents, or contrast agents, will enhance the signal in specific regions as the agent gets distributed throughout the body by altering $\mathrm{T}_{1}, \mathrm{~T}_{2}$ or both. ${ }^{16}$ Most commonly used contrast agents are gadolinium(III) complexes, small paramagnetic metal complexes, which shorten the relaxation times of the water protons by increasing the rate of longitudinal water proton relaxation and thereby result in an increase of signal intensity. ${ }^{18,19}$ The relaxivity of an agent is known as the water proton relaxation rate per unit concentration of contrast agent and an increase in relaxivity results in a more effective reduction in $\mathrm{T}_{1}{ }^{19}$ However, $\mathrm{Gd}^{3+}$-based agents have their drawbacks as well. Current $\mathrm{Gd}^{3+}$ contrast agents flow throughout all extracellular space, have comparatively low relaxivities of $4-5 \mathrm{mM}^{-1} \mathrm{~s}^{-1}$ [2] and must be provided in comparatively high doses of about $0.1 \mathrm{mmol} \mathrm{kg}^{-1}{ }^{19}$

A new group of contrast agents have been found by Balaban et $a l^{16}$, which may be used for MRI. These agents possess slowly exchanging $-\mathrm{NH}$ or $-\mathrm{OH}$ protons and operate through a Chemical Exchange Saturation Transfer, or CEST, of pre-saturated spins to bulk water. ${ }^{16,17}$ In a CEST mechanism a nucleus is exchanged from one site to a chemically different site. ${ }^{18}$ This process is

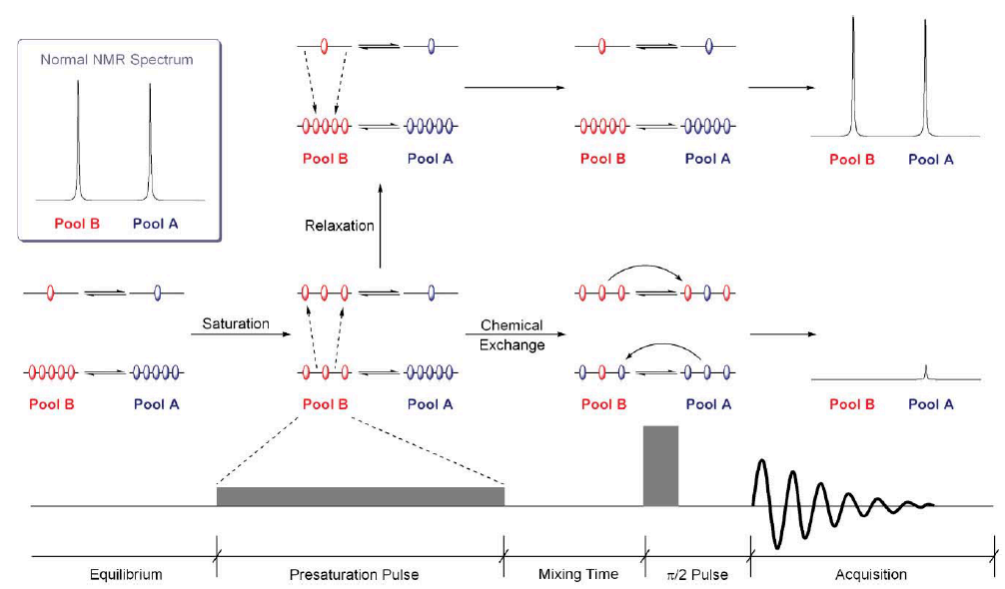

Figure 2. When a presaturation pulse is applied to Pool B the number of high energy spins increases. Given that the chemical exchange rate is large enough to overcome the effects of relaxation, chemical exchange will occur. If not, the high energy spins will relax back to equilibrium. ${ }^{18}$ 
in competition with relaxation and can be seen in Figure $2 .{ }^{18}$ The CEST process would occur in a system that has two pools, $\mathrm{A}$ and $\mathrm{B}$, of exchanging protons as long as the pools have relaxation times that are longer than the exchange rates. ${ }^{18}$ The exchange rates should also be as fast as possible to reduce relaxation effects. ${ }^{18}$ Following a presaturation pulse, Pool A would have an increase in high energy spins, against the magnetic field, and a decrease in low energy spins, along the magnetic field. ${ }^{18}$ This moves Pool A closer to saturation, reducing the bulk magnetization and the signal intensity. Pool B would have a signal intensity of almost $0 .{ }^{18}$ Using this mechanism, signal intensity of one resonance can therefore be altered by applying a presaturation pulse to a second resonance that is in exchange with the first resonance and ultimately use this effect to change signal intensity to produce contrast in MRI images. ${ }^{18}$ Paramagnetic compounds that have exchangeable proton sites (-NH, $-\mathrm{OH}$ or $\mathrm{H}_{2} \mathrm{O}$ ) frequency shifted away from the bulk water NMR frequency may increase the effectiveness of a CEST agent by maximizing the frequency difference between the two pools, $\Delta \omega$, and consequently also the rate of chemical exchange. ${ }^{18}$ These compounds are called PARACEST agents. Another advantage of PARACEST agents is their ability to act as "smart" agents and respond to changes in molecular concentrations within the body. ${ }^{18}$ So far, systems that are capable of reporting a number of biologically relevant variables have been constructed, such as: $\mathrm{pH}$, temperature, lactate, glucose and zinc. ${ }^{1}$

Divalent zinc is the second most abundant transition-metal ion in the human body ${ }^{4,9,11,14}$ and deficiency in the ion affects digestive, immune and neuronal systems. ${ }^{10,14,15}$ It has also been found to be important for regulation of cell death and synaptic transmission, ${ }^{3}$ but perhaps most importantly $\mathrm{Zn}^{2+}$ is bound up with insulin in pancreatic $\beta$-cells. Because $\mathrm{Zn}^{2+}$ is co-released with insulin in response to elevated glucose levels imaging the presence of $\mathrm{Zn}^{2+}$ could be beneficial to 
the medical field and to understanding diabetes in particular. In the human body, $\mathrm{Zn}^{2+}$ exists both as bound $\mathrm{Zn}^{2+}$ and free $\mathrm{Zn}^{2+}$. Bound $\mathrm{Zn}^{2+}$ can be found on membrane receptors, transporters and channels regulating their activity. ${ }^{7}$ Bound $\mathrm{Zn}^{2+}$ on loosely bound metal-protein complexes in certain cell types and organelles are released to form free $\mathrm{Zn}^{2+}$ ion concentrations ranging from $10^{-12}-10^{-5} \mathrm{M}$ to about $0.3 \mathrm{mM} .^{1,5,8}$ To be able to study how and why it is released inside the body a mode of detection will be necessary. In the past there has been success in sensing $\mathrm{Zn}^{2+}$ ions using $\mathrm{Gd}^{3+}$ complexes, where the first one designed decreased water relaxivity by about $30 \%$ when $\mathrm{Zn}^{2+}$ was present. ${ }^{6}$ A CEST agent with $\mathrm{Eu}^{3+}$ has also been designed and was shown to be promising in sensing $\mathrm{Zn}^{2+}$ concentrations that were within range for free $\mathrm{Zn}^{2+}$ ions in human tissues. $^{13}$

\section{Methods}
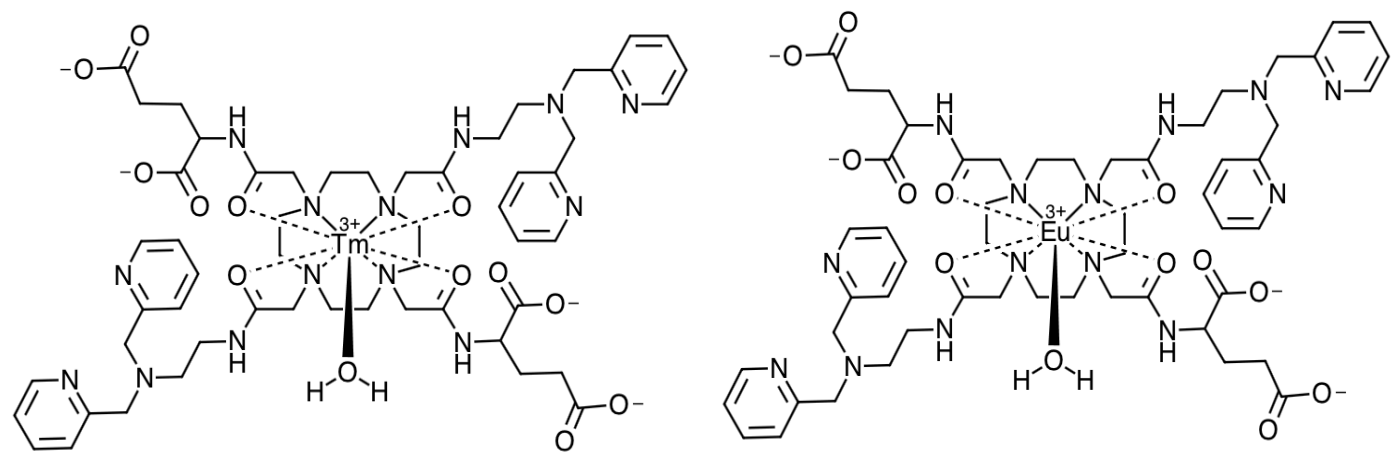

Figure 3. The two contrast agents studied were the thulium complex (left) and europium complex (right).

Two contrast agents were studied, including a thulium complex and a europium complex. The structures of these contrast agents can be seen in Figure 3. Each complex was studied in four separate samples of varying $\mathrm{Zn}^{2+}$ concentration: $0,0.5,1$, and $2 \mathrm{Eq} \mathrm{Zn}^{2+}$. They were then analyzed on a Bruker $600 \mathrm{MHz}$ NMR spectrometer to obtain $\mathrm{T}_{1}$ values of bulk water. All $\mathrm{T}_{1}$ values were measured through saturation recovery except for the europium with zero equivalents 
of $\mathrm{Zn}^{2+}$, which was measured through inversion recovery. The $\mathrm{T}_{1}$ values were then used to fit the data on MATLAB software.

\section{Results}

The $\mathrm{T}_{1}$ values for the $\mathrm{Tm}^{3+}$ samples with $0,0.5,1$ and 2 equivalents of $\mathrm{Zn}^{2+}$ were $0.377 \mathrm{~s}, 0.370$ $\mathrm{s}, 0.365 \mathrm{~s}$, and $0.396 \mathrm{~s}$ respectively. The $\mathrm{T}_{1}$ values for the $\mathrm{Eu}^{3+}$ samples with the same $\mathrm{Zn}^{2+}$ equivalents were $3.384 \mathrm{~s}, 2.489 \mathrm{~s}, 2.559 \mathrm{~s}$, and $2.587 \mathrm{~s}$ respectively.

\begin{tabular}{|c|c|c|c|c|}
\hline${\text { Eqs of } \mathbf{Z n}^{\mathbf{2}}}^{+}$ & $\mathbf{0}$ & $\mathbf{0 . 5}$ & $\mathbf{1}$ & $\mathbf{2}$ \\
\hline$[$ EuL] (mM) & 12.778 & 8.333 & 6.945 & 5.833 \\
\hline $\boldsymbol{\tau}_{\mathbf{M}}(\mathbf{u s})$ & 293.3 & 105.1 & 76 & 67.2 \\
\hline $\boldsymbol{\tau}_{\mathbf{N H}}(\mathbf{m s})$ & 5 & 0.9588 & 0.84 & 0.5009 \\
\hline $\boldsymbol{\delta} \mathbf{H}_{\mathbf{2}} \mathbf{O}$ & 0.3357 & 0.5913 & 0.4711 & 0.4644 \\
\hline $\boldsymbol{\delta}$ bound & 50.8941 & 50.8218 & 50.6135 & 49.3208 \\
\hline $\boldsymbol{\delta} \mathbf{~ N H}$ & -4.5 & -5.0554 & -4.8617 & -5.1599 \\
\hline $\mathbf{T}_{\mathbf{1}}$ bulk & 2.48 & 2.25 & 2.55 & 2.58 \\
\hline $\mathbf{T}_{\mathbf{2}}$ bulk & 0.6748 & 0.8082 & 0.8576 & 0.5707 \\
\hline $\mathbf{T}_{\mathbf{1}}$ bound & 0.045 & 0.03 & 0.03 & 0.03 \\
\hline $\mathbf{T}_{\mathbf{2}}$ bound & 0.01 & 0.01 & 0.01 & 0.01 \\
\hline $\mathbf{T}_{\mathbf{1}} \mathbf{N H}$ & 1.5 & 1.5 & 1.5 & 1.5 \\
\hline $\mathbf{T}_{\mathbf{2}} \mathbf{N H}$ & 1.5 & 0.3 & 0.3001 & 1.5 \\
\hline
\end{tabular}

Table 1. Fitting parameters for the $\mathrm{Eu}^{3+}$ chelate.

\begin{tabular}{|c|c|c|c|c|}
\hline$[\mathbf{Z n}]=$ & $\mathbf{0}$ & $\mathbf{0 . 5}$ & $\mathbf{1}$ & $\mathbf{2}$ \\
\hline $\boldsymbol{\tau}_{\mathbf{M}}(\boldsymbol{\mu s})$ & 2711.3 & 4094 & 972.1 & 1465.5 \\
\hline $\boldsymbol{\tau}_{\mathbf{N H}}(\mathbf{m s})$ & 2.169 & 1.2081 & 2.9585 & 0.7353 \\
\hline $\boldsymbol{\delta} \mathbf{H}_{\mathbf{2}} \mathbf{O}$ & -0.1747 & -0.2936 & -0.4485 & -0.7757 \\
\hline $\boldsymbol{\delta}$ bound & -48.2598 & -47.5 & -51.5 & -50.7996 \\
\hline $\boldsymbol{\delta}$ NH & -51.8 & -52 & -59.5 & -59.6928 \\
\hline $\mathbf{T}_{\mathbf{1}}$ bulk & 0.3806 & 0.3719 & 0.3669 & 0.3999 \\
\hline $\mathbf{T}_{\mathbf{2}}$ bulk & 0.0045 & 0.0045 & 0.0053 & 0.0091 \\
\hline $\mathbf{T}_{\mathbf{1}}$ bound & 0.0005 & 0.0006 & 0.1396 & 0.0018 \\
\hline $\mathbf{T}_{\mathbf{2}}$ bound & 0.001 & 0.001 & 0.0004 & 0.0003 \\
\hline $\mathbf{T}_{\mathbf{1}} \mathbf{N H}$ & 0.0005 & 0.0012 & 0.2 & 0.0019 \\
\hline $\mathbf{T}_{\mathbf{1}} \mathbf{N H}$ & 0.0006 & 0.0003 & 0.0045 & 0.0003 \\
\hline
\end{tabular}

Table 2. Fitting parameters for the $\mathrm{Tm}^{3+}$ chelate.

The $T_{1}$ of bulk water was constrained to these $T_{1}$ values and CEST spectra were fitted to the Bloch equations using a three-pool model of bulk, bound and $\mathrm{NH}$. The other $\mathrm{T}_{1}$ and $\mathrm{T}_{2}$ values 
were constrained to reasonable values. The fitting parameters are shown in Table 1 and 2 for the $\mathrm{Eu}^{3+}$ and $\mathrm{Tm}^{3+}$ chelates respectively.
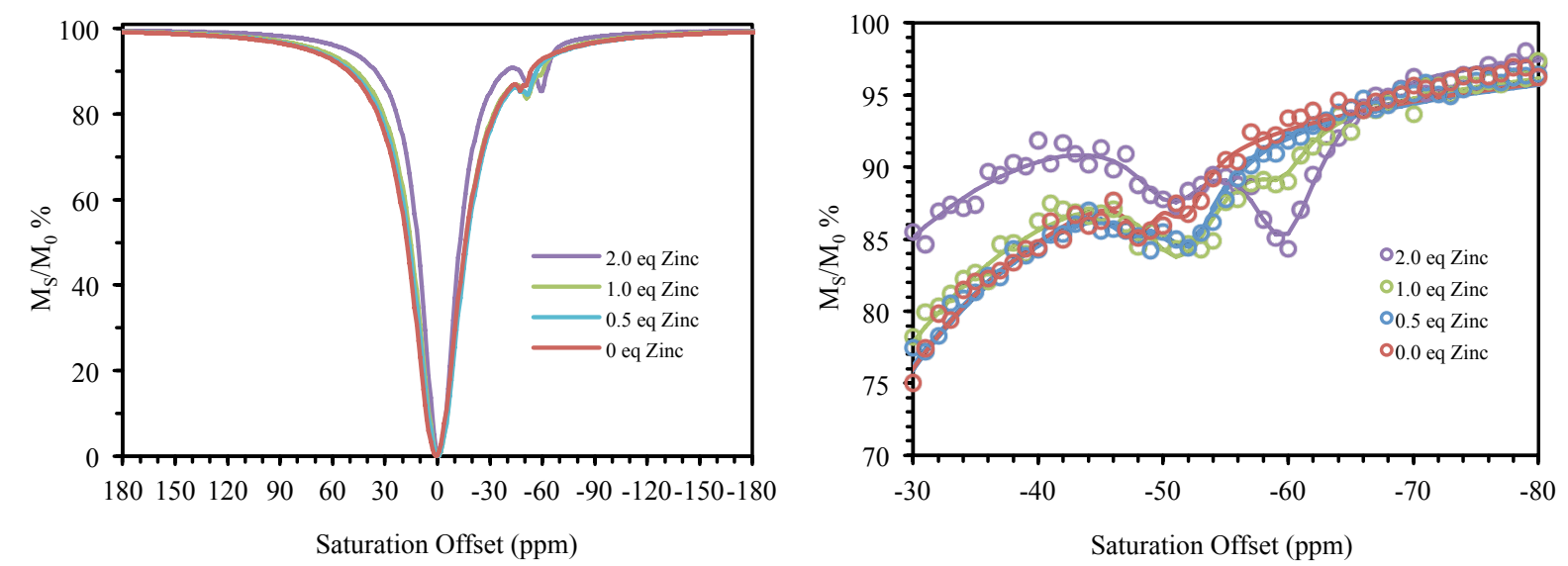

Figure 4. Full CEST spectra of the $\mathrm{Tm}^{3+}$ chelate with $0,0.5,1$ and 2 equivalents of $\mathrm{Zn}^{2+}$ (left) and just the two amide peaks (right).

The full CEST spectra of the $\mathrm{Tm}^{3+}$ chelate (Figure 4) was visualized for the four samples. The two peaks corresponding to the amide protons, which were expected for a chelate with $\mathrm{C}_{2}$ symmetry, can be seen closer on the right of Figure 4. Prior to any addition of $\mathrm{Zn}^{2+}$ the two CEST peaks were at $-48 \mathrm{ppm}$ and $-52 \mathrm{ppm}$, with the downfield, $-48 \mathrm{ppm}$, peak having greater intensity. At half of an equivalent of $\mathrm{Zn}^{2+}$ the peaks were at the same location, however the upfield peak, $-52 \mathrm{ppm}$, became ore intense. After the addition of one equivalent of $\mathrm{Zn}^{2+}$ the two amide peaks shifted to $-52 \mathrm{ppm}$ and $-60 \mathrm{ppm}$ with the downfield peak, $-52 \mathrm{ppm}$, being more

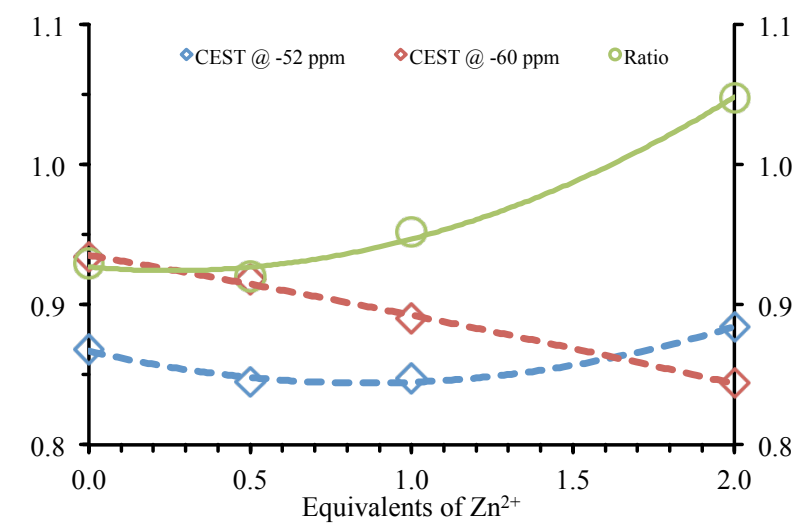

Figure 5. CEST for the two amide protons at $-52 \mathrm{ppm}$ and $-60 \mathrm{ppm}$ on the $\mathrm{Tm}^{3+}$ chelate with increasing $\mathrm{Zn}^{2+}$ concentration. Ratio of the two is represented by the curve above. 
intense. At two equivalents of $\mathrm{Zn}^{2+}$ the peaks experienced no shift, however the upfield peak, -60 ppm, was the most intense. Overall, with increasing concentrations of $\mathrm{Zn}^{2+}$, CEST at $-60 \mathrm{ppm}$ decreased from 0.934 to 0.844 and CEST at $-52 \mathrm{ppm}$ increased from 0.868 to 0.884 (Figure 5). The ratio of -52 to -60 increased from 0.93 to 1.05 as the concentration of $\mathrm{Zn}^{2+}$ increased.
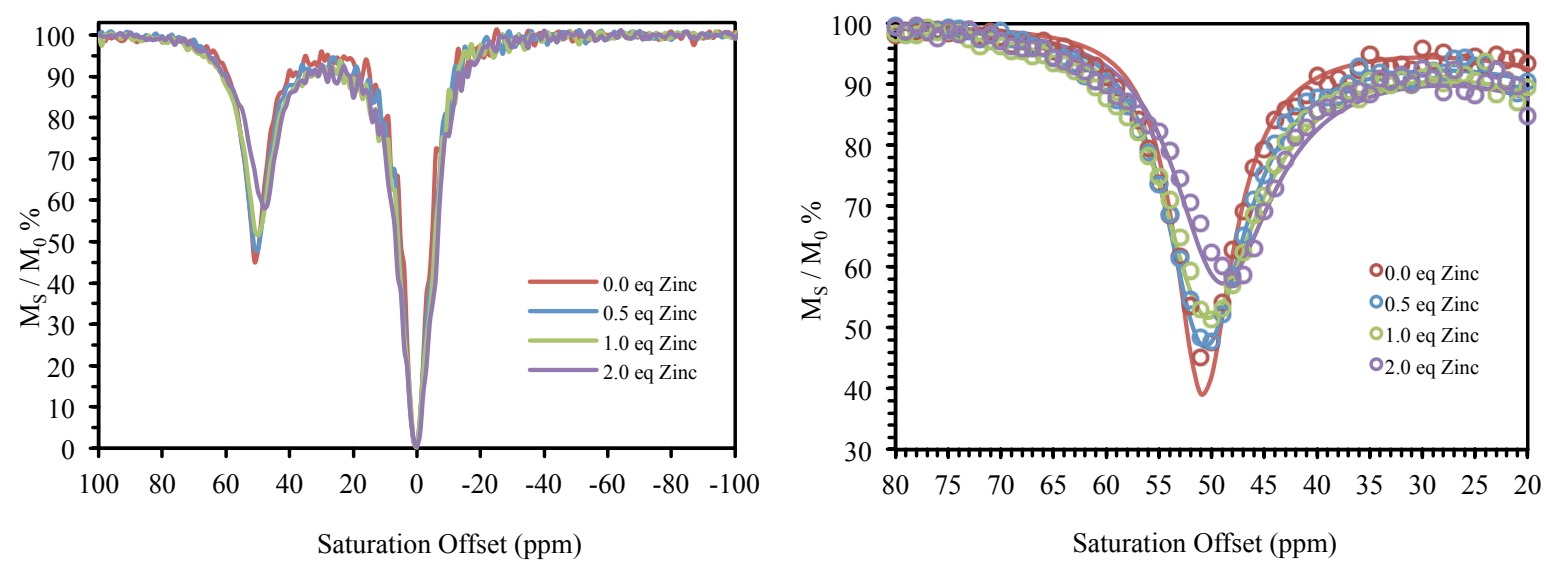

Figure 6. Full CEST spectra of the $\mathrm{Eu}^{3+}$ chelate with $0,0.5,1$ and 2 equivalents of $\mathrm{Zn}^{2+}$ (left) and just the bound water peak (right).

CEST spectra of the $\mathrm{Eu}^{3+}$ chelate (Figure 6) showed the bound water peak at $50 \mathrm{ppm}$ and the bulk water peak centered at $0 \mathrm{ppm}$. A closer view of the bound water peak shows that as the concentration of $\mathrm{Zn}^{2+}$ increases, the peak broadens, reduces in intensity and shifts toward the bulk water peak upfield. Titration of the $\mathrm{Eu}^{3+}$ chelate with 0 to 2.25 equivalents of $\mathrm{Zn}^{2+}$ resulted

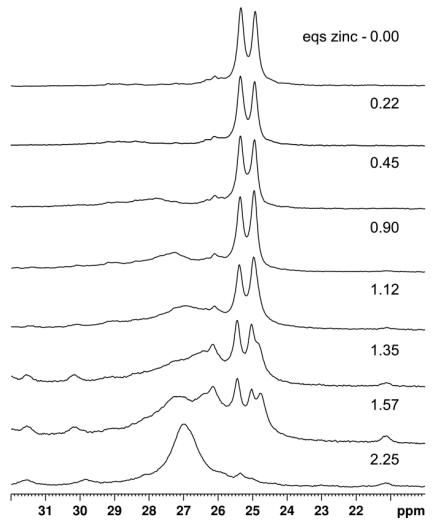

Figure 7. ${ }^{1} \mathrm{H}$ NMR Spectrum from titrating the $\mathrm{Eu}^{3+}$ chelate with varying concentrations, 0 to 2.25 equivalents, of $\mathrm{Zn}^{2+}$. 
in a noticeable change in the ${ }^{1} \mathrm{H}$ NMR spectrum with increasing $\mathrm{Zn}^{2+}$ concentration, especially exceeding one equivalent (Figure 7).

\section{Discussion}

The shift of the amide protons in the CEST spectra of the $\mathrm{Tm}^{3+}$ chelate makes it likely that there is a different chelate structure in the presence of $\mathrm{Zn}^{2+}$ than when $\mathrm{Zn}^{2+}$ is absent. This was supported by the change in the ${ }^{1} \mathrm{H}$ NMR spectrum following titration of $\mathrm{Zn}^{2+}$ into a solution of the $\mathrm{Eu}^{3+}$ chelate. When examining the CEST spectra of the two amide protons it can be seen that the upfield CEST peak without $\mathrm{Zn}^{2+}$ and the downfield CEST peak with $\mathrm{Zn}^{2+}$ both occur at -52 ppm, but vary in their intensity. This change in intensity in the presence of $\mathrm{Zn}^{2+}$ could make it usable as a marker for $\mathrm{Zn}^{2+}$ concentration. The peak at $-60 \mathrm{ppm}$ can be used as a reporter of the $\mathrm{Zn}^{2+}$ concentration in a ratiometric method, but the peak at $-48 \mathrm{ppm}$ may be too weak. Figure 4 further indicates the presence of multiple species as $\mathrm{Zn}^{2+}$ is added to solution. The line broadening is the result of individual species having different shifts as well as the changing exchange rate. This causes the appearance of deceivingly faster exchange rates. It may also explain why the concentration of chelate appears to decrease with increasing $\mathrm{Zn}^{2+}$ concentrations.

The broadening, shifting, and reduction in intensity of the bound water peak of the $\mathrm{Eu}^{3+} \mathrm{CEST}$ spectra indicates that water exchange kinetics are increasing with the presence of $\mathrm{Zn}^{2+}$. The fit was also not adequate on the bound water peaks when concentration of the CEST agent was kept constant and consistent with the known initial concentration. Only when the concentration was progressively decreased for each sample did the data fit better. The concentration values in Table 1 also show that with added $\mathrm{Zn}^{2+}$ a reduction in the hydration state or exchange capacity of the CEST agent is observed. 


\section{Acknowledgements}

I wish to thank Dr. Mark Woods for allowing me to be a part of the Woods Research Group and for advising me throughout this project. I would also like to thank the rest of the research group for always being welcoming and helpful. A special thank you to Joseph Armstrong and Nicole Lamar for training me and patiently answering my questions throughout my time in the lab. 


\section{References}

1. Budde, T.; Minta, A.; White, J. A.; Kay, A. R. Imaging Free Zinc in Synaptic Terminals in Live Hippocampal Slices. Neuroscience 1997, 79, 347.

2. Caravan, P.; Ellison, J. J.; McMurry, T. J.; Lauffer, R. B. Gadolinium(III) Chelates as MRI Contrast Agents: Structure, Dynamics, and Applications. Chem. Rev. 1999, 99, 2293.

3. Choi, D. W.; Koh, J. Y. Zinc and Brain Injury. Annu. Rev. Neurosci. 1998, 21, 347-375.

4. Coleman, J. E. Zinc Enzymes. Curr. Opin. Chem. Biol. 1998, 2, 222.

5. Frederickson, C. Imaging Zinc: Old and New Tools. Sci. STKE 2003, 182, pe18.

6. Hanaoka, K.; Kikuchi, K.; Urano, Y.; Nagano T. Selective Sensing of Zinc Ions with a Novel Magnetic Resonance Imaging Contrast Agent. J. Chem. Soc. Perkin Trans. 2 2001, 1840.

7. Huang, E. P. Metal Ions and Synaptic Transmission: Think Zinc. Proc. Natl. Acad. Sci. USA 1997, 94, 13386.

8. Outten, C. E.; O'Halloran, T. V. Femtomolar Sensitivity of Metalloregulatory Proteins Controlling Zinc Homeostasis. Science 2001, 292, 2488.

9. Parkin, G. Synthetic Analogues Relevant to the Structure and Function of Zinc Enzymes. Chem. Rev. 2004, 104, 699.

10. Prasad, A. S. Zinc: an Overview. Nutrition 1995, 11, 93.

11. Sandrom, B. Considerations in Estimates of Requirements and Critical Intake of Zinc, Adaption, Availability and Interactions. Analyst 1995, 120, 913.

12. Stark, D. D.; Bradley W. G. Magnetic Resonance Imaging; Mosby Inc.: St. Louis, 1999; Vol. 1, pp 1-5. 
13. Trokowski, R.; Ren, J.; Kálmán, F. K.; Sherry, D. A. Selective Sensing of Zinc Ions with a PARACEST Contrast Agent. Angew. Chem. Int. Ed. 2005, 44, 6920-6923.

14. Vallee, B. L.; Falchuk, K. H. Biochemical Basis of Zinc Physiology. Physiol. Rev. 1993, 73, 79 .

15. Wapnir, R. A. Zinc Deficiency, Malnutrition and the Gastrointestinal Tract. J. Nutr. 2000, 130, 1388S.

16. Ward, K. M.; Aletras A. H.; Balaban, R. S. A New Class of Contrast Agents for MRI Based on Proton Chemical Exchange Dependent Saturation Transfer (CEST). J. Magn. Reson. 2000, 143, 79-87.

17. Ward, K. M.; Balaban, R. S. Determination of pH Using Water Protons and Chemical Exchange Dependent Saturation Transfer. Magn. Reson. Med. 2000, 44, 799.

18. Woods, M.; Woessner, D. E.; Sherry, D. A. Paramagnetic Lanthanide Complexes as PARACEST Agents for Medical Imaging. Chem. Soc. Rev. 2006, 35, 500-511

19. Woods, M.; Zhang, S.; Sherry, D. A. Toward the Design of MR Agents for Imaging $\beta$ Cell Function. Curr. Med. Chem. 2004, 4, 349-369. 